\section{Fixed ratio schedule of reinforcement as a determinant of successive discrimination reversal learning in the pigeon*}

\author{
BEN A. WILLIAMS \\ The Colorado College, Colorado Springs, Colo. 80903
}

Pigeons, trained on a series of blue-green discrimination reversals and then on a series of red-yellow discrimination reversals, were required to emit either 1 or 15 pecks per trial. Those pigeons with the FR 15 requirement improved more rapidly across successive reversals for both problems, with the magnitude of the effect being larger for the more difficult discrimination problem.

Successive discrimination reversal learning (SDR) has been increasingly used as a tool of the comparative psychology of learning. Considerably less research has been devoted to a functional analysis of SDR behavior for any particular species. Without such analysis, species differences revealed by the SDR procedure remain potentially interpretable as products of confounded variables correlated with species differences. A prerequisite for interpreting any species difference in the SDR procedure, therefore, is a specification of the determinants of SDR behavior in general.

One variable of potential significance for SDR behavior is the response requirement. In previous experiments (Williams, 1971a, b) examining the acquisition of a different complex learning problem (nonspatial delayed alternation), the author has found that pigeons required to emit $10-15$ pecks per trial learned to alternate between two colors, even with delays as long as $45 \mathrm{sec}$ between trials, whereas pigeons required to emit 1-5 pecks per trial showed no learning. The present study extends the analysis of the FR variable to the SDR procedure in order to determine whether or not response requirement affects other types of complex discrimination learning.

$$
\text { SUBJECTS }
$$

Twelve White Carneaux pigeons were maintained at $80 \%$ of their free-feeding body weight. Six Ss were experimentally naive; three had been trained previously on an auditory generalization task using variable-interval schedules of reinforcement; and three had been trained on a red-green discrimination reversal procedure 18 months prior to the start of this experiment.

*This experiment was conducted when the author was a NSF graduate fellow and was supported by Research Grants WIS supported by Research Grants NIMH 15494 and NIH-GM-15258 to
Harvard University. Reprints can be obtained from the author. The Colorado College, Colorado Springs, Colo. 80903 keys was a $5.0 \times 4.5 \mathrm{~cm}$ aperture through which the birds were fed when a food magazine was activated. The relay programming for the chamber was located in an adjoining room.

\section{PROCEDURE}

After shaping the birds to peck the left key while illuminated with white light, training on a red-yellow discrimination problem was presented. Yellow was the correct stimulus for Day 1, red on Day 2, yellow on Day 3, etc., with this continuing for a total of 10 sessions. Within a daily problem, each color was present on each trial. When the correct color was pecked, the lights were extinguished and the $\mathrm{S}$ was rewarded with $2.8-\mathrm{sec}$ access to the food magazine, followed by $1.2 \mathrm{sec}$ of complete darkness before the start of the next trial. When the incorrect color was pecked, the lights were extinguished for the entire 4.0-sec interval between trials. With the exceptions of Days 1 and 2, when a noncorrection procedure was used, the positions of the colors changed randomly after a correct trial but did not change after an incorrect trial. Training within a session continued until the bird reached the criterion of 20 consecutively correct trials.

For Sessions 1 and 2, all Ss were trained using only one peck per trial (FR 1). Thereafter, one-half of the Ss were required to emit at least 15 pecks per trial (FR 15). With this procedure, correct and incorrect pecks were counted separately so that whichever first reached the FR 15 requirement determined whether the trial was

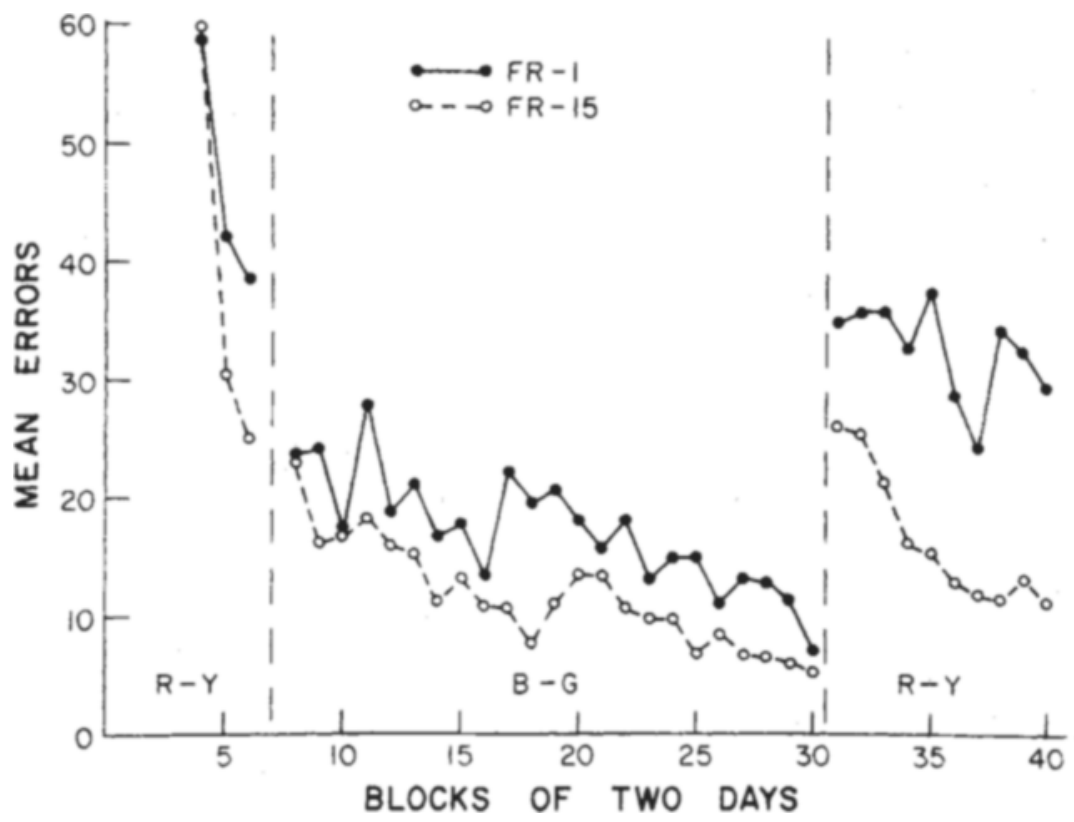

Fig. 1. Mean number of errors per session (trials completed on incorrect stimulus) on the red-yellow and blue-green reversal problems. 
correct or incorrect.

After 10 sessions of red-yellow training ( $R-Y)$, the blue-green problem (B-G) was introduced, with no other changes being made in the daily procedure. During B-G training, occasional single-stimulus pretraining was presented to four Ss in each FR group. This pretraining in no way affected the FR comparisons, however, and its effects are not presented here. Training on the B-G problem was continued for 56 reversals.

After completion of B-G training, the colors were returned to the original R-Y problem. This training continued for 20 reversals.

\section{RESULTS}

The data from each of the three phases of training are presented in Fig. 1. The first four sessions of the initial $R-Y$ training are not shown because of the shaping required for the FR 15 behavior to become stable. Figure 1 reveals that both groups of Ss gradually learned reversals with increasing proficiency but that FR 15 Ss required fewer errors per reversal. To test this observation statistically, Ss from the two FR groups were paired according to their training history with difference scores then computed for their respective mean errors per problem. The mean difference was subjected to a t test and was found to be significant for both B-G training [ probability, one-tailed $t(5)=2.10<.05]$ and the second phase of R-Y training [probability, one-tailed, $t(5)=3.71<.01]$.

In addition to the overall FR effect, Fig. 1 suggests an interaction between FR value and difficulty of the discrimination. For all FR $1 \mathrm{Ss}$, many more errors were emitted during $R-Y$ training than during $\mathrm{B}-\mathrm{G}$ training, hence indicating that $R \cdot Y$ was the more difficult problem. Much less difference was apparent, however, for the FR 15 Ss. To test for this interaction, difference scores for the second $R-Y$ training were compared with difference scores for the first 20 sessions of $\mathrm{B}-\mathrm{G}$ training, with a $\mathrm{t}$ test then performed on the differences of the differences. The mean difference of the differences was 9.9 errors per reversal and was statistically significant [ probability, two-tailed, $t(5)=3.12<.05]$. Thus, the more difficult the discrimination problem, the more important the $F R$ variable becomes.

The immediate question raised by the FR requirement's considerable effect on SDR learning proficiency is its mechanism. Since several different response parameters were correlated with the ratio requirement (e.g., effortfulness, duration), some further analysis of the actual mechanism of the facilitative effect would seem desirable. One observation pertinent to this question, from a previous experiment, was the distribution of pecks within a trial. Although the overall accuracy for individual responses was only slightly less than overall accuracy for trials, Williams (1971a) found a persistent tendency for the initial pecks of a trial to be less accurate than later pecks in the trial. The inaccuracy of the initial pecks was not the result of random behavior, however, but instead was specifiable as the result of perseverative errors (the problem was delayed alternation learning). The larger FR requirements allowed such perseverative errors to be overcome within a trial. Whether a similar explanation accounts for the present results with a different learning problem, where sources for perseverative errors are less obvious, is not answerable by the available data.

A second question regarding the FR effect, regardless of its mechanism, is its generality across species. For example, can SDR learning in fish be facilitated by a FR requirement? Although no data are available on this question, it is noteworthy that qualitative differences in learning proficiency in other complex learning problems have previously been shown with pigeons (Williams, 1971a)

\section{REFERENCES}

WILLIAMS, B. A. Color alternation learning in the pigeon under fixed ratio schedule of reinforcement. Journal of the Experimental Analysis of Behavior $1971 \mathrm{a}, 15,129 \cdot 140$.

WILLIAMS, B. A. Non-spatial delayed alternation by the pigeon. Journal of the Experimental Analysis of Behavior. $1971 \mathrm{~b}, 16,15-21$.

\section{CURRENT LITERATURE ON DISCRIMINATION LEARNING IN ANIMALS}

BEALE, I. L. (Dalhousie University, Halifax, Nova Scotia, Canada), \& WILLIAMS, R. J. Experimental control of beak shift during tests for interocular transfer of a lateral mirror-image discrimination. Psychonomic Science, 1971, 24, 7-8.

CRADDOCK, S. N., JR., \& THOMPSON, R. (Louisiana State University, Baton Rouge, La. $\left.\begin{array}{lllll}7 & 0 & 8 & 0 & 3\end{array}\right)$. A dis c rete interpedunculo-central tegmental region critical for retention of visual discrimination habits in the white rat. Journal of Comparative \& Physiological Psychology, 1971, 76, 39-50.

FARTHING, G. W. (University of Maine, Orono, Maine 04473). Effect of a signal previously paired with free food on operant response rate in pigeons. Psychonomic Science, $1971,23,343-344$.

GROSS, C. G. (Princeton University Princeton, N.J. 08540), COWEY, A., \& MANNING, F. J. Further analysis of visual discrimination deficits following foveal prestriate and inferotemporal lesions in rhesus monkeys. Journal of Comparative \& Physiological Psychology, 1971, 76, 1.7.

HEIN, A. (Massachusetts Institute of Technology, Cambridge, Mass. 02139), \& DIAMOND, R. M. Independence of the cat's scotopic and photopic systems in acquiring control of visually guided behavior. Journal of Comparative \& Physiological Psychology, 1971, 76, 31-38.

HYMAN, A. (Adelphi University, Garden City, N.Y. 11530). The effect of removal of the warning stimulus from a schedule of free operant avoidance. Psychonomic Science, 1971, 24, 46-48.

MEANS, L. W. (East Carolina University, Greenville, N.C. 27834), HARDY, W. T., GABRIEL, M., \& UPHOLD, J. D. Utilization of odor trails by rats in maze learning. Journal of Comparative \& Physiological Psychology, 1971, 76, 160-164.

RUSSO, J. D. (George Washington University, Washington, D.C. 20006). Observational learning in hooded rats. Psychonomic Science,
$1971,24,37-38$

SHARP, L. F. (U.S. Air Force Academy, Colo. 80840). Learning as a function of territory-related behavior patterns in the blue gourami (Trichopterus trichopterus). Psychonomic Science, $1971,23,323-324$.

SOUTHALL, P. F. (Memphis State University, Memphis, Tenn. 38111), \& LONG, C. J. Odor stimuli, training procedures, and performance in a T-maze. Psychonomic Science, 1971, 24, 4-6.

STRATTON, L. O. (Louisiana State University in New Orleans, New Orleans, La. 70122), \& EDWARDS, S. Preference and sensory factors in brightness discrimination learning of posterior neodecorticated albino rats. Psychonomic Science, 1971, 24, 9-10.

TRAUPMANN, K. L. (University of Texas at Austin, Austin, Tex. 78712), \& WONG, P. T. P. CRF pretraining and differential magnitude discrimination. Psychonomic Science, 1971, 24, 20-21. 